\title{
Acceptability of the "MOVEdiabetes" physical activity intervention in diabetes primary care settings in Oman: findings from participants and practitioners
}

\author{
Thamra S. Alghafri ${ }^{*}$ (D), Saud M. Al Harthi ${ }^{2}$, Fatma Al-Ajmi ${ }^{2}$, Yahya Al-Farsi ${ }^{3}$, Angela M. Craigie $^{4}$,
} Elaine Bannerman ${ }^{5}$ and Annie S. Anderson ${ }^{4}$

\begin{abstract}
Background: Adequate physical activity (PA) is considered essential in diabetes management. However, evidence on the best method of promoting PA within diabetes care is inconclusive. The current work identifies perceptions on the acceptability of Intervention Group Participants (IGP) and Project Officers (POs) about the "MOVEdiabetes" intervention programme aimed at increasing PA in adults with type 2 diabetes in Oman (a retrospectively registered trial).
\end{abstract}

Methods: The "MOVEdiabetes" programme (PA consultations, pedometers and WhatsApp messages) was delivered by the POs (primary health care practitioners) in four primary care centres within a one-year cluster randomised control trial. Recruitment and retention were measured from trial attendance records. Programme satisfaction, appropriateness, and content suitability were assessed using exit surveys for both the IGP (interview based) and POs (self-administered). Open text questions on perceptions to the study programme were also included.

Results: Participants were randomised to an intervention group (IG, $n=122)$ or comparison group (CG, $n=110)$. The overall retention rate at three and 12 months was $92.7 \%$ [110(90.2\%) IG vs 105(95.5\%) CG] and 75\% [82(67.2\%) IG vs 92(83.6\%) CG] respectively. Most ( $n=14,87.5 \%)$ POs and more than half $(n=49,59.8 \%)$ IGP perceived the programme as very appropriate and many reported that they were "quite/ very satisfied" with the programme $(n=$ $16,100 \%$ PO's and $n=71,86.6 \%$ IGP). Two thirds ( $n=55,66.0 \%)$ of IGP were very/quite likely to recommend the programme to others. PA consultations, use of pedometers and Whatsapp messages were well perceived by all. Participants recommended the inclusion of dietary advice and PA promotion for the general public. Exploring PA facilities within the community was suggested by POs.

Conclusions: The "MOVEdiabetes" programme achieved a high retention rate and was perceived as satisfactory and appropriate. Results from this study suggest that it is worthwhile exploring the use of the "MOVEdiabetes" programme in clinical practice and further community links.

(Continued on next page)

\footnotetext{
* Correspondence: thamra74@yahoo.com

1 Directorate General of Health Services, Ministry of Health, Muscat, Oman \&

University of Dundee, PO Box 2723, Postal Code 112 Muscat, Oman

Full list of author information is available at the end of the article
}

C The Author(s). 2020 Open Access This article is licensed under a Creative Commons Attribution 4.0 International License, which permits use, sharing, adaptation, distribution and reproduction in any medium or format, as long as you give appropriate credit to the original author(s) and the source, provide a link to the Creative Commons licence, and indicate if changes were made. The images or other third party material in this article are included in the article's Creative Commons licence, unless indicated otherwise in a credit line to the material. If material is not included in the article's Creative Commons licence and your intended use is not permitted by statutory regulation or exceeds the permitted use, you will need to obtain permission directly from the copyright holder. To view a copy of this licence, visit http://creativecommons.org/licenses/by/4.0/. The Creative Commons Public Domain Dedication waiver (http://creativecommons.org/publicdomain/zero/1.0/) applies to the data made available in this article, unless otherwise stated in a credit line to the data. 
(Continued from previous page)

Trial registration: International Standard Randomised Controlled Trials No: ISRCTN14425284. Registered retrospectively on 12th April 2016.

Keywords: Physical activity, Type 2 diabetes, Primary health care, MOVEdiabetes, Intervention, Oman, Recruitment and retention

\section{Background}

Despite the strong evidence base for the inclusion of PA in the clinical management of diabetes [1], the majority of PA interventions have been performed in a controlled research setting, using resource intensive methods of short duration and limited follow-up [2]. Minimal information is available on how acceptable these interventions are when adapted and implemented within everyday practice [3].

Despite the reported barriers to promoting PA in clinical settings such as a lack of time, training and assessment tools [4], some methods to facilitate and support behavioural changes regarding PA in primary care have proven to be effective in several studies in Western cultures [5-7]. Current research in this area includes understanding components of PA interventions, barriers and motivators and effective methods of intervention delivery. However, few studies have examined the perceived appropriateness, suitability of interventions and implications of trial findings for roll out within local settings.

Moreover, to address cultural, social and clinical differences, it is important to evaluate the acceptability and appropriateness of transferring evidence from the West to the Arab world. Evaluating these aspects is important for further programme development and improvement, ensuring accountability to stakeholders and helping others set up similar services.

The use of process evaluations to guide the translation of research findings for effective clinical practice is increasing. However, a lack of consistent reporting of the evaluation findings remains an issue $[8,9]$.

Due limited evidence, in the Arabic world and Oman, series of studies were structured to provide formative evidence to inform a PA behavioural intervention within diabetes primary care in Oman. Results from formative work that has informed the design of a PA intervention named "MOVEdiabetes" have been published in several recognized international journals [4, 10-12]. To follow, the "MOVEdiabetes" intervention examined the impact of a multi-component intervention/trial (PA consultations, pedometers and WhatsApp phone messages) to increase PA in inactive adults with T2D in Oman. This paper describes the perceptions of the participants in the intervention group (IG) and all the project officers (POs) (health care practitioners in primary health care), of the
"MOVEdiabetes" study in order to establish if the intervention (published elsewhere) was acceptable [10, 13].

\section{Methods}

The study was a 1 year (April 2016 to June 2017) cluster randomized controlled trial of the "MOVEdiabetes" intervention versus usual care. The trial aimed at evaluating the effectiveness of the intervention on changes in PA levels (primary outcome), anthropometric (weight and BMI), and cardio-vascular outcome at 12 months from baseline [10]. Notably, the published "MOVEdiabetes" trial adhered to the CONSORT guidelines [13]. Health centres were randomised to deliver either the intervention (IG, $n=4$ ) or usual care in the comparison group (CG, $n=4)$. The intervention group received the "MOVEdiabetes" personalised PA consultations, a pedometer (YAMAX Digi-walker SW-200) to measure weekly step counts and monthly WhatsApp support messages. Intervention delivery was undertaken by all members of the POs except for conducting the consultations which were confined to the dietitians only (maximum $20 \mathrm{~min}$ ) on three occasions (0,4 and 8 weeks). Participants were asked to set individual goals and complete daily (personal diaries) step counts which were to be submitted to the POs in their respective health centres at 3 and 12 months follow up shared through the WhatsApp phone application. Monthly standardised PA motivational messages, coinciding with religious and international occasions [such as Ramadhan, breast feeding day, cancer awareness day, and healthy lifestyle awareness day were all delivered through the WhatsApp telephone application [10].

The "MOVEdiabetes" intervention was effective in increasing PA levels, reducing sitting time and increasing the likelihood of meeting WHO PA recommendations in adults with T2D attending their routine diabetes primary care clinics over 12 month. Additionally, the intervention showed potentially protective cardiovascular effectiveness in reducing blood pressure and triglycerides levels [13].

The POs were required to undertake short meetings with the PI last week of every month to discuss attendance sheets, issues with the PA consultations, and participant appointment slots. Equally important, every effort was made to give the participants convenient appointments and reschedule appointments when needed. 
Additionally, the smart phones (specific for the "MOVEdiabetes" study) were used to facilitate the communication between the POs and PI. The WhatsApp telephone application (in addition to its use for intervention purposes) and phone calls were used throughout the study period to manage the daily logistics and administrative queries.

Worth mentioning, the ethical approval for this study was obtained from the Regional Research Committee in Muscat, Oman Ministry of Health within the overall "MOVEdiabetes" study.

\section{Details on measures/assessment instruments}

Two questionnaires guided by some of the key components on program implementation, maintenance and fidelity, outlined by Linnan and Steckler [14] were developed to assess POs' and IG participants' perceived acceptability of the programme. The questions were in the format of 5-point Likert scales that included 11 items for participants and eight items for POs. Potential responses were anchored with a scale that ranged from positive to negative perceptions to the items in the questionnaires (Tables 1 and 2). Additionally, a number of open-ended questions, were included to explore perceptions from the POs and participants on areas were more information was required, challenges and general comments. Both surveys were developed to be completed at the end of trial (exit survey) (see Supplementary files 1 and 2).

To maximise content validity for selection of items/ questions, the revision process of the questionnaires involved assessment by the authors of this study (EB, AMC and ASA) and two independent PA researchers from Oman (SMA, FA, and YF) and a subsequent revision in light of their feedback by TSA. Prior to field administration, an internal pilot testing with a convenience sample of adults with T2D $(n=10)$ was carried out. Minor changes were made to ensure clear understanding and smooth flow of the questions including re-arranging and locating the questions and responses.

\section{Participants' exit survey}

The 11-item survey was an interviewer-led questionnaire administered by an independent nurse/researcher who interviewed the participants who completed 12 months study follow up $(n=82)$ and recorded their responses. All participants who attended the 12-month visit were approached and invited to complete the survey.

The items explored overall satisfaction of the project (from 'very dissatisfied' to 'neither satisfied nor dissatisfied' to 'very satisfied'), if information received regarding the project was enough (from 'too little' to 'sufficient information' to 'too much information'), if they had enough opportunities to ask questions (from 'not at all' to 'every once in a while' to 'very often') and if answers to their questions were satisfactory (from 'not at all' to 'every once in a while' to 'completely satisfactory'). Additionally, the survey included questions on the likelihood of recommending the intervention to others (from 'very unlikely' to 'neither likely nor unlikely' to 'very likely'), accessibility to the health centres (from 'very difficult' to 'neither easy nor difficult' to 'very easy'), and if the intervention was appropriate in diabetes care (from 'not at all appropriate' to 'neither appropriate or inappropriate' to 'very appropriate'). Participants were also asked if they perceived their PA behaviour change to be acceptable (from 'not at all' to 'not sure' to 'very acceptable').

To follow, participants were asked to rate each intervention component (face to face consultations, pedometers and use of WhatsApp) from a range of five options from 'very poor' to 'acceptable' to 'very good' (Table 1 ). The consultations were rated for their content, relevance, duration and frequency. Pedometers on the other hand were rated for length of the device use, importance to diabetes care, longevity, and usefulness. Finally, WhatsApp communications were rated for their content, relevance, time required, frequency of messages, and supportiveness (Table 1).

Four open ended questions queried participants' perceptions of: a) aspects of the project where more information was needed, b) challenges of taking part in the project, c) barriers to increasing physical activity behaviour, and d) general comments.

\section{Project officers' exit survey}

The POs were recruited from existing health care providers (doctors/nurses/dietitians/health educators) involved in diabetes primary care. Project officers received study specific training on the recruitment procedures, screening the participants, recording outcome measurements, and delivering the "MOVEdiabetes" intervention in intervention health centres. A self-reported eight-item (five-point Likert scale) based questionnaire was completed by all POs at the end of the "MOVEdiabetes" study. Questions included overall satisfaction with the intervention (from 'very dissatisfied' to 'neither satisfied nor dissatisfied' to 'very satisfied'), if training received prior to the intervention delivery was enough (from 'far too little' to 'sufficient information' to 'far too much'), if they had opportunities to ask questions (from 'not at all' to 'every once in a while' to 'very often') and if the answers to their questions were satisfactory (from 'not at all' to 'every once in a while' to 'completely'). An additional question was included on the appropriateness of the intervention in diabetes care (from 'not at all appropriate' to 'not sure' to 'very appropriate'). Also, individual components of the "MOVEdiabetes" intervention namely use of pedometers, WhatsApp and PA consultations, 


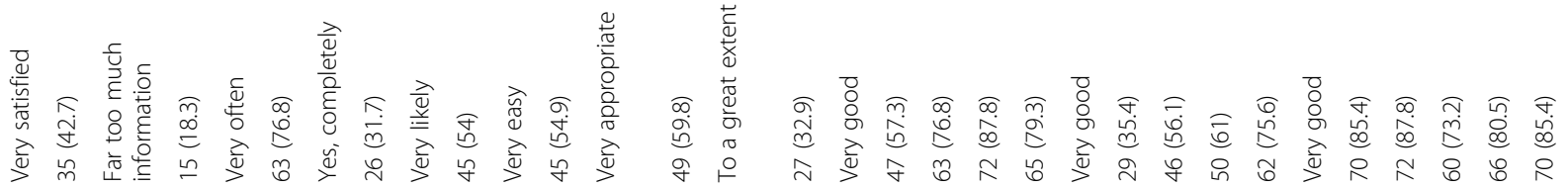

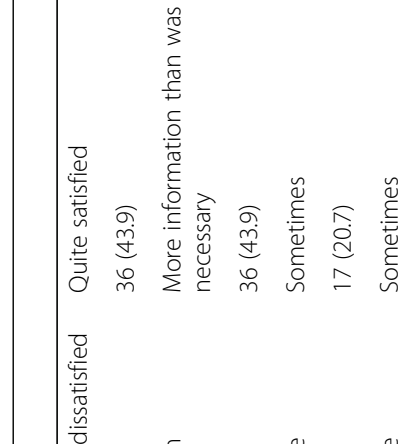

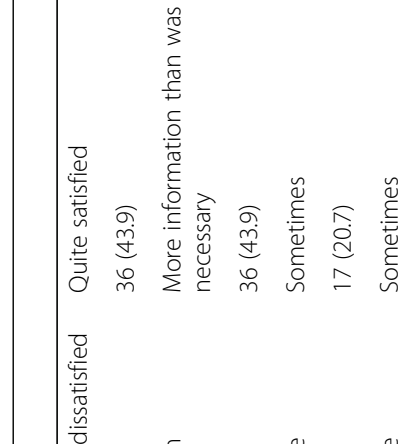

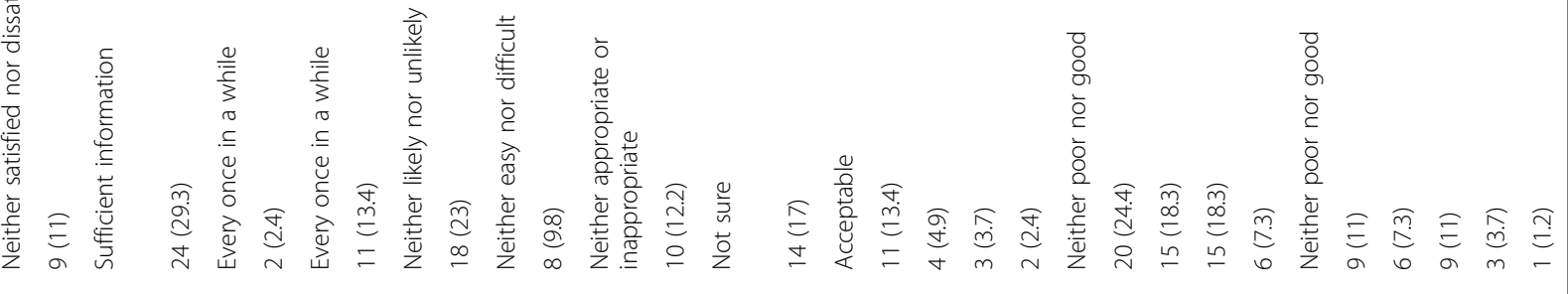

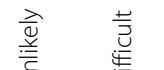

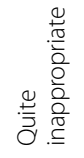
竞

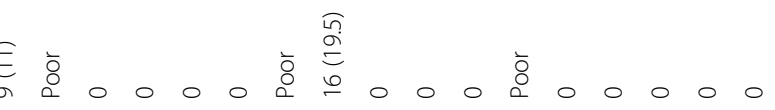

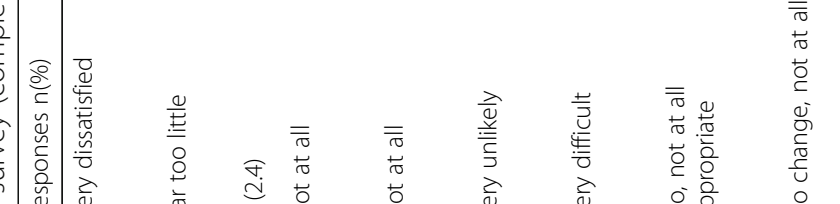

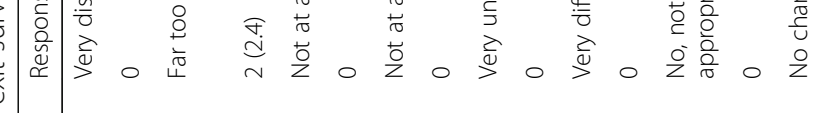

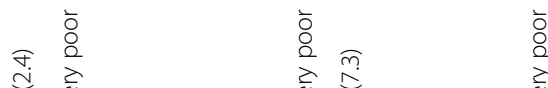
$\frac{1}{i}$ 


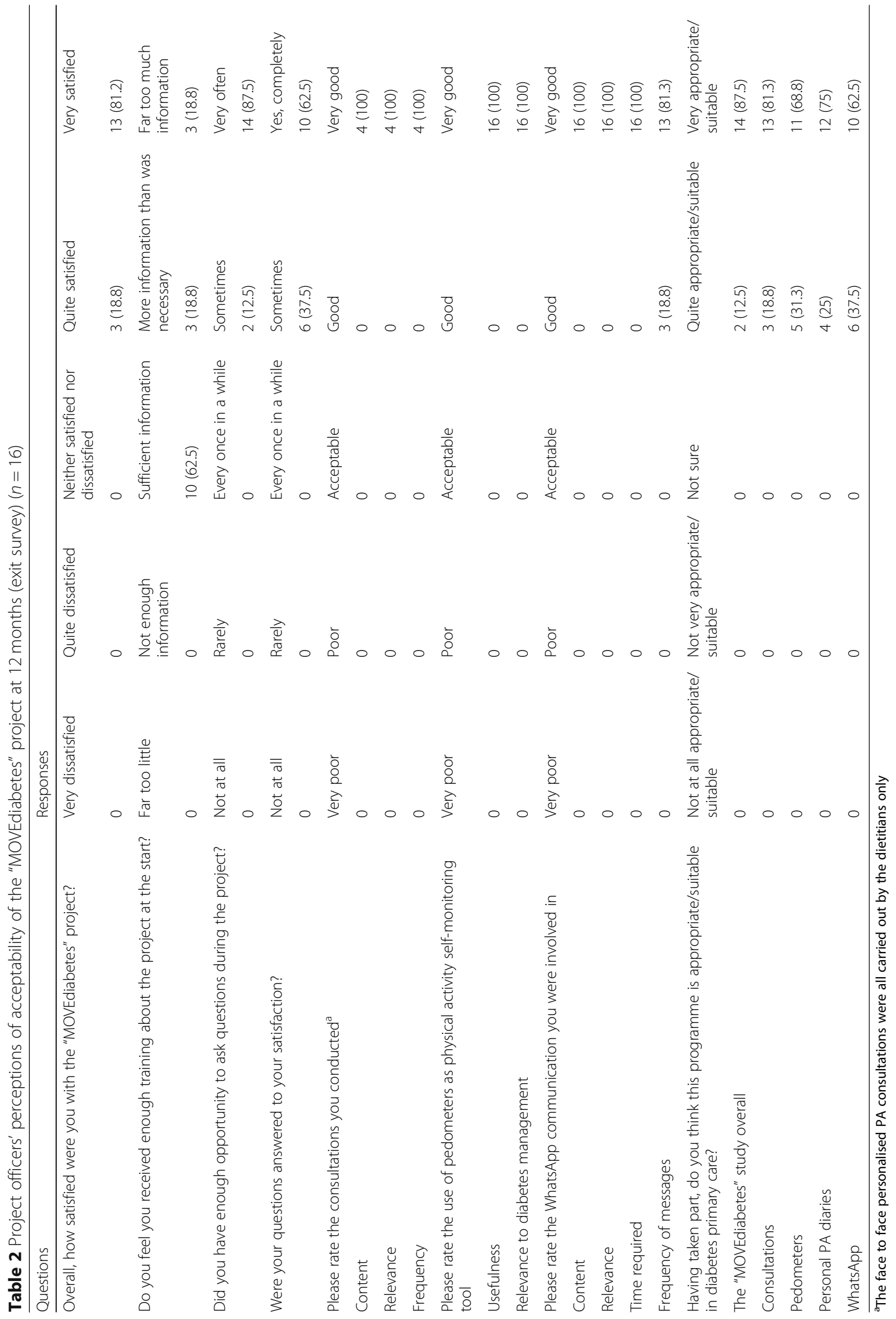


were rated (from 'very poor' to 'acceptable' to 'very good') by POs in terms of content, relevance, and frequency of the PA consultations. For use of pedometers, ratings were on their usefulness and relevance. WhatsApp communications on the other hand, were rated for content, relevance, time required and frequency of messages. Finally, a general question on the suitability of each of the intervention components in diabetes care was included ('not at all suitable' to 'not sure' to 'very suitable'). Additionally, open-ended questions were used for POs to document their perceptions on topics which required more information, for example, any challenges to delivering the intervention and if they had any further comments.

\section{Analysis}

Mixed methods were used to analyse data on acceptability: Frequency tables were used to present response numbers (n) and proportions (\%) for all items in the questionnaires using IBM SPSS Statistics for Windows (V 22).

Open ended questionnaire responses were transcribed verbatim and analysed using thematic content analysis [15]. Initial responses were read several times by the principal investigator (TSA) followed by open coding, grouping and categorizing data according to emerging themes. A coding scheme was then developed based on the major recurring themes. Themes were cross-checked by another independent researcher (SA) and areas of contradiction were discussed and adjusted. A final revision was carried out by one of the authors (YF) as a further measure of inter-rater reliability.

\section{Results}

\section{Recruitment and retention}

Out of 232 enrolled participants (117 IG, 110 CG) completed measurements at baseline. Overall retention was 92.7\% [110(90.2\%) IG vs 105(95.5\%) CG] at3 and 75\% [82(67.2\%) IG vs $92(83.6 \%) \mathrm{CG}]$ at 12 months.

\section{Participant exit survey}

Overall, results presented in Table 1 indicate positive response. All participants in the IG who completed the 12 months visit $(n=82)$ responded to the exit questionnaire (38 male, 44 female). Most participants were 'very satisfied' $(n=35,42.7 \%)$ or 'quite satisfied' ( $n=36,43.9 \%)$ with the project. Only $11 \%(n=9)$ were 'not sure' and very few were 'quite dissatisfied' $(n=2,2.4 \%)$.

Most participants felt the information received was 'more than necessary' or 'sufficient information' (43.9 and $29.3 \%$, respectively) although a fifth of the participants thought it was 'far too much' (18.7\%). In addition, participants reported positively to their opportunity to ask questions and satisfaction to the answers.
Overall, responses were largely positive with $66 \%$ indicating they were very/quite likely to recommend the project to others. Other participants were unsure (23\%) and few were 'very unlikely' (11\%).

Accessibility to respected health centres was very/quite easy to majority of the participants and most participants perceived the project as 'very appropriate' and 'quite appropriate' for use within local diabetes primary care.

\section{Perceptions on intervention response and components}

Two thirds of the participants perceived their PA behaviour to have changed to a 'great extent' and 'somewhat'. However, a third (30.4\%) were 'not sure' or experienced 'very little' change or 'no change'.

Responses about longevity were less positive (49\% reported the longevity of the pedometers to be 'good' or 'very good', however most perceived their importance to diabetes management, wearing them and usefulness as 'good' to 'very good'.

Except for use of pedometers (length of device use), no one responded 'poor' or 'very poor' to any of the other intervention components. Content, relevance, duration of the PA consultations and frequency were all perceived as 'good' to 'very good' by most of the participants. Additionally, responses about the WhatsApp monthly messages were all perceived as 'fairly good' to 'very good' by the majority of the participants.

\section{Project officers' exit survey}

Sixteen POs participated (2 male and 14 female) in intervention delivery and data collection across the eight randomly selected health centres: eight doctors, four nurses and 4 dietitians (Table 2). The PA consultations were delivered by the dietitians only. Overall responses were all positive. All POs were either 'very satisfied' or 'quite satisfied' with the project although three POs considered it excessive.

Opportunity to ask questions and answers were all well perceived by the majority of the POs. All the dietitians $(n=4)$ who delivered the face to face personalised PA consultations perceived the consultations as 'very good' for content, relevance and frequency. Additionally, all POs perceived the pedometers as useful and relevant to diabetes management. Content, relevance, and time required for activation of WhatsApp messages were perceived as 'very good'. Perceptions on the frequency of WhatsApp messages were 'very good' by majority of POs.

Overall the intervention was perceived as 'very appropriate' or 'quite appropriate' by all POs. Moreover, suitability of all the "MOVEdiabetes" components (consultations, pedometers, personal PA diaries and WhatsApp messages) 
were perceived as 'quite' to 'very suitable' with no negative or neutral responses.

\section{Responses to the open questions}

Responses from the participants?

Responses to the open questions varied across the questions (see Supplementary file 3).

Overall, 43.9\% of the participants expressed an interest in knowing more about types of exercises "What type of exercise is suitable for patients with diabetes? P_HC1", the use of accelerometers "What is the purpose of the accelerometers? P_HC1", and PA options in the presence of comorbidities "I have glaucoma, can I exercise? $P_{-}$ HC2".

Only $25.6 \%$ participants responded to the question on challenges of taking part in this project. Two themes were identified as challenges of taking part in the project: long and exhausting measurement tools "The questionnaires are too long and time-consuming P_HC4" and lack of time for intervention delivery "I don't have time to attend the PA consultations $P_{-} H C 2$ ".

Barriers to increasing PA behaviour were identified by 43.9\% participants. Main barriers were: hot weather "It is too hot outside, I can't walk P_HC4", lack of time "I have no time for physical activity $P_{-} H C 1$ ", resources "I don't know where to go for physical activity P_HC4", and pain "I can't exercise, I have pain in my knees $P_{-} H C 2$ ".

Finally, general comments from $24.3 \%$ participants were themed as: inclusion of dietary advice "I suggest to add diet advice P_HC2", project sustainability "Keep the project, don't stop P_HC3", and a similar project for all including children and the public "Develop similar projects for children/public P_HC3 EP_HC1".

Responses from the POs?

Notably, number/percentage of responses from the POs $(n=16)$ varied across the questions. Three quarters $(75 \%, n=12)$ of the POs provided responses to the open question on topics which required more information in the survey and are listed in full as verbatim quotes in Supplementary file 4. Among those who responded to this question, half of them reported that they required more information on the PA behaviour change techniques (BCT) "We need more PA training especially on the behaviour change techniques PO1", and PA measurement tools "More information is needed on the measurement tools or devices PO1".

Themes identified for challenges $(n=16)$ to delivering the intervention were categorised as physical challenges and logistical challenges including: "No dedicated room/ space PO3", "Busy clinics PO2", "Long questionnaires PO16", "Managing appointments is difficult PO5", and "Handling accelerometers is difficult PO10".

Themes to the general comments from the POs $(n=$ 14) were related to sustaining the project "WhatsApp
Communications may be useful for future PA interventions PO8" and "Include PA in the Health information system PO3". Additionally, importance of identifying available PA facilities in communities was highlighted "Implement this project in all health centres PO12" and "We need information on the available PA facilities in the nearby community PO5".

\section{Discussion}

\section{Implications of study results on the current practice and} future studies

This paper aimed to provide evidence on the perceived acceptability of the "MOVEdiabetes" study to POs and participants in the IG. Overall, the majority of the IG participants (who completed the 12 months study period) and all POs were satisfied with the "MOVEdiabetes" study. Additionally, the majority of the participants perceived the programme as appropriate within primary diabetes care in Oman. The fact that this intervention was delivered in a primary care setting may have enhanced intervention implementation and acceptance as this setting has been reported as being effective for PA promotion [16-19]. Primary health care is considered as one of seven best investments by the Global Advocacy for PA [20, 21]. It is therefore reassuring for interested researchers to upscale the current study or develop similar PA interventions within diabetes clinical settings.

Opportunities to ask questions and feedback were well received by both the participants and POs. In fact, the information received was perceived as 'more than necessary' or 'far too much' by more than half of the participants. A future assessment may be needed to explore which aspects of the project require more information.

The communications in the "MOVEdiabetes" study were accessible and flexible throughout the study period. Participants had options for interactive communications with their peers and/or POs through WhatsApp or face to face contacts in the health centres within the scheduled visits to diabetes clinics. This may have initiated a positive social atmosphere for PA support [22]. This feature may have contributed to their willingness to recommend the project to others and to their subjective perceptions of improvements in their PA behaviour. Findings from the literature confirmed the positive effects of psycho-social influences namely self-efficacy and social support on levels of PA [22-27]. However, future studies may consider exploring robust ways for effective and sustainable communications including providing information and feedback in promoting PA in diabetes care.

The intervention components used in the "MOVEdiabetes" study were a practical translation of the recommendations from the formative work carried out to 
inform the PA intervention design [10, 13]. This study demonstrated that the "MOVEdiabetes" intervention components (face to face personalised PA consultations, pedometer and WhatsApp use) within routine diabetes primary care were satisfactory, appropriate and acceptable by the majority of the participants and POs. However, some participants perceived the longevity, defined as the period of time within which the device (pedometers) was operating well, as 'very poor' or 'poor' (device stopped working/recording the steps taken/day). This may indicate the need to consider devices with better quality and longer longevity especially with the current available pedometers in the market. Most importantly, participants need to understand the limitations of pedometers including risk of falling and damage (For example pedometer use in swimming).

It is evident that the WhatsApp, PA consultations and pedometer use was highly rated by participants. The POs on the other hand, gave more positive ratings for delivering the consultations, pedometers and then WhatsApp use. POs may value clinical based settings for consultations as a normal part of their daily work and may not have time to engage in additional (outside the clinic) communications [4, 28, 29]. This challenge was possibly diluted by the fact that the project was managed by a team of four members in each of the health centres who took turns to give feedback to participants. On the other hand, the participant/patients may have considered the WhatsApp communications as an additional flexible tool to discuss their health condition with their health care providers. This may have facilitated the establishment of a better patient-provider relationship reflected in the high participants' satisfaction on the opportunities to ask questions and getting answers/feedback reported earlier. The positive effects of using the WhatsApp phone application in promoting PA has been reported in few studies [30]. However, more information is required on the longterm use of phone and text applications on promoting healthy behaviours.

Two research perspectives were identified as challenging by the participants and POs. Firstly, the multiple questionnaires (GPAQ, self-efficacy, social support, general well-being and exit questionnaires) used in this study were viewed as too long and time consuming. However, it is important to note that these were used for research purposes and may not be used within the common routine diabetes clinics. Future simpler versions of those questionnaires may be warranted for service evaluation purposes if these were to be integrated within the routine diabetes primary care. Secondly, delivery of the PA intervention was linked to pre-scheduled visits to diabetes clinics. Due to the dynamic and busy nature of the diabetes primary clinics as reported by the POs, future interventions may test the effectiveness of "stand alone" PA clinics that patients could be referred to vs the integrative "MOVEdiabetes" approach [31]. However, the fact that most participants found coming to the clinic for visits easy, may be attributed to the integrative approach adapted in the current study.

Similar to many studies in nearby countries, [32-34] hot weather was cited as a barrier by responders from the "MOVEdiabetes" study indicating the importance of discussing options for indoor PA and/or weather friendly timings for PA. However, addressing extreme weather conditions in promoting PA is under reported $[35,36]$.

Finally, participants highlighted the desire for advice on diet as an adjunct to PA and also for similar PA promotion projects to be available for all (the general population). These recommendations are of direct relevance to the National Health Policy Priorities in Oman [37]. To promote the health awareness of the community and establish a culture of healthy lifestyles" [37, 38].

With respect to the POs, qualitative data indicates a desire for more training on PA behaviour change techniques and measurement tools [4]. This may be essential for the continuation of the capacity building activities in PA across health care professions.

Challenges to delivering the intervention by the POs were similar to those reported in the literature e.g. the physical and logistical constraints within the structure of primary health care (e.g. small rooms and lack of space) [3]. Future extension of this project could explore the optimal approaches to re-structure and organise the routine diabetes clinics to make them friendly to PA promotion for both patients and health care providers.

\section{Study limitations}

The interviewer led approach may have discouraged the participant from giving negative comments and more work may be needed to explore views and perceptions using anonymous approaches. Also, bias cannot be excluded as answers to the open ended questions were limited to those who responded and it is possible that non-responders may have not been interested or entirely satisfied.

Moreover, the current exit surveys looked at perceptions from the intervention group only; future studies may consider exploring views from the comparison groups too. This would confirm if the perceptions on the study programme were actually different between the study groups e.g. perceptions of changed behaviours. 


\section{Conclusions}

The "MOVEdiabetes" study was perceived as satisfactory, appropriate and suitable. Overall, the suggested alterations to the PA intervention (inclusion of advice on diet, PA trainings, shorter PA evaluative tools, integration of PA in the current HIS, and links to community resources) are hoped to lead to a sustainable PA service within the current primary health care setting that could be made available for the general population.

\section{Supplementary information}

Supplementary information accompanies this paper at https://doi.org/10. 1186/s12889-020-09029-1.

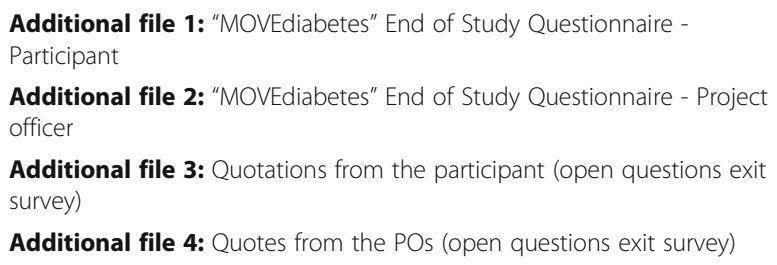

Additional file 3: Quotations from the participant (open questions exit survey)

Additional file 4: Quotes from the POs (open questions exit survey)

\section{Abbreviations}

PA: Physical activity; T2D: Type 2 diabetes; IGP: Intervention Group Participants; POs: Project Officers; IG: Intervention group; CG: Comparison group; GPAQ: Global physical activity questionnaire; (Scot-PASQ): The Scottish Physical Activity Screening Questionnaire

\author{
Acknowledgments \\ Many thanks to: \\ - Dr. Adil Al Wehabi for his constant support \\ - All those who took part in the "MOVEdiabetes" study. \\ - The POs within the primary care who supported and engaged with the \\ study.
}

\section{Authors' contributions}

TS supervised the analysis of this data, interpreted the data and wrote the manuscript; SA and FA interpreted the data and reviewed the manuscript. $Y A, A C, E B$, and $A A$ supervised, reviewed the study proposal, assessment tools, interpretation of data and the manuscript. All authors read and approved the final manuscript.

\section{Funding}

Oman Ministry of Health and research council has funded The "MOVEdiabetes" project as part of PhD grants offered to the corresponding author (TSA). The funding body in Ministry of health was not involved in data collection, analysis, and interpretation and/or in writing the manuscript.

\section{Availability of data and materials}

Data generated from this study is not available for public use. However it is available from the corresponding author on reasonable request and approvals from Oman Ministry of Health.

\section{Ethics approval and consent to participate}

Ethical approval was obtained from the Regional Research Committee in Ministry of Health within the overall "MOVEdiabetes" study. All eligible participants provided informed written consent prior to data collection.

\section{Consent for publication}

Not applicable.

\section{Competing interests}

The authors declare that they have no competing interests.

\section{Author details}

${ }^{1}$ Directorate General of Health Services, Ministry of Health, Muscat, Oman \& University of Dundee, PO Box 2723, Postal Code 112 Muscat, Oman. ${ }^{2}$ Directorate General of Health Services, Ministry of Health, Muscat, Oman. ${ }^{3}$ Department of Family Medicine and Public Health, College of Medicine and Health Sciences, Sultan Qaboos University, Muscat, Oman. ${ }^{4}$ Centre for Public Health Nutrition Research, Ninewells Hospital and Medical School, University of Dundee, Dundee, UK. ${ }^{5}$ Global Academy of Agriculture \& Food Security, The Royal (Dick) School of Veterinary Studies, University of Edinburgh, Edinburgh, UK.

Received: 14 September 2019 Accepted: 1 June 2020

Published online: 08 June 2020

\section{References}

1. Colberg SR, Sigal RJ, Yardley JE, Riddell MC, Dunstan DW, Dempsey PC, Horton ES, Castorino K, Tate DF. Physical activity/exercise and diabetes: a position statement of the American Diabetes Association. Diabetes Care. 2016;39(11):2065.

2. Matthews L, Kirk A, MacMillan F, Mutrie N. Can physical activity interventions for adults with type 2 diabetes be translated into practice settings? A systematic review using the RE-AIM framework. Transl Behav Med. 2014;4(1):60-78.

3. van Sluijs EMF, van Poppel MNM, Stalman WAB, van Mechelen W. Feasibility and acceptability of a physical activity promotion programme in general practice. Fam Pract. 2004;21(4):429-36.

4. Alghafri TS, Alharthi SM, Al-balushi S, Al-Farsi Y, Al-busaidi Z, Bannerman E, Craigie AM, Anderson AS. Health professionals' perceptions about physical activity promotion in diabetes care within primary health care settings in Oman. Heliyon. 2017;3(12):e00495.

5. Matthews L, Kirk A, McCallum M, Mutrie N, Gold A, Keen A. The feasibility of a physical activity intervention for adults within routine diabetes care: a process evaluation. Pract Diabetes. 2017;34(1):7-12a.

6. Avery L, Charman SJ, Taylor L, Flynn D, Mosely K, Speight J, Lievesley M, Taylor R, Sniehotta FF, Trenell MI. Systematic development of a theoryinformed multifaceted behavioural intervention to increase physical activity of adults with type 2 diabetes in routine primary care: movement as medicine for type 2 diabetes. Implement Sci. 2016;11(1):99.

7. Kirk A, Barnett J, Leese G, Mutrie N. A randomized trial investigating the 12month changes in physical activity and health outcomes following a physical activity consultation delivered by a person or in written form in type 2 diabetes: Time2Act. Diabet Med. 2009;26(3):293-301.

8. Grant A, Treweek S, Dreischulte T, Foy R, Guthrie B. Process evaluations for cluster-randomised trials of complex interventions: a proposed framework for design and reporting. Trials. 2013;14(1):15.

9. Matthews L. The feasibility, effectiveness and implementation of a physical activity consultation service for adults within routine diabetes care. In: Implementation of physical activity services for the management of adults with type 2 diabetes. Glasgow: University of Strathclyde School of Psychological Sciences and Health; 2013.

10. Alghafri TS, Alharthi SM, Al-Farsi YM, Craigie AM, McLeod M, Anderson AS. Study protocol for "MOVEdiabetes": a trial to promote physical activity for adults with type 2 diabetes in primary health care in Oman. BMC Public Health. 2017;17(1):28.

11. Alghafri TS, Alharthi SM, Al-farsi Y, Bannerman E, Craigie AM, Anderson AS. Correlates of physical activity and sitting time in adults with type 2 diabetes attending primary health care in Oman. BMC Public Health. 2017;18(1):85.

12. Alghafri T, Alharthi SM, Al Farsi YM, Bannerman E, Craigie AM, Anderson AS. Perceived barriers to leisure time physical activity in adults with type 2 diabetes attending primary healthcare in Oman: a cross-sectional survey. BMJ Open. 2017;7(11):e016946.

13. Alghafri TS, Alharthi SM, Al-Farsi Y, Alrawahi AH, Bannerman E, Craigie AM, Anderson AS. 'MOVEdiabetes': a cluster randomized controlled trial to increase physical activity in adults with type 2 diabetes in primary health in Oman. BMJ Open Diabetes Res Care. 2018;6(1):e000605.

14. Linnan $L$, Steckler A. Process evaluation for public health interventions and research: an overview. In: Steckler A, Linnan L, editors. Process evaluation for public health interventions and research. San Francisco: Jossey-Bass; 2002.

15. Virginia, Victoria. Successful qualitative research a practical guide for beginners. 1st ed. Croydon: SAGA publications Ltd; 2013. 
16. Cobiac $\amalg$, Vos T, Barendregt JJ. Cost-effectiveness of interventions to promote physical activity: a modelling study. PLoS Med. 2009;6(7):e1000110.

17. Marcus BH, Williams DM, Dubbert PM, Sallis JF, King AC, Yancey AK, Franklin BA, Buchner D, Daniels SR, Claytor RP. Physical activity intervention studies: what we know and what we need to know: a scientific statement from the American Heart Association Council on Nutrition, Physical Activity, and Metabolism (Subcommittee on Physical Activity); Council on Cardiovascular Disease in the Young; and the Interdisciplinary Working Group on Quality of Care and Outcomes Research. Circulation. 2006;114(24):2739-52.

18. Eakin EG, Brown WJ, Marshall AL, Mummery K, Larsen E. Physical activity promotion in primary care: bridging the gap between research and practice. Am J Prev Med. 2004;27(4):297-303.

19. Ashenden R, Silagy C, Weller D. A systematic review of the effectiveness of promoting lifestyle change in general practice. Fam Pract. 1997;14(2):160-76.

20. Investments that work for physical activity [www.globalpa.org.uk].

21. Bull FC, Milton KE. A process evaluation of a "physical activity pathway" in the primary care setting. BMC Public Health. 2010;10(1):463.

22. Lindsay Smith G, Banting L, Eime R, O'Sullivan G, van Uffelen JGZ. The association between social support and physical activity in older adults: a systematic review. Int J Behav Nutr Phys Act. 2017;14(1):56.

23. Gleeson-Kreig JM. Self-monitoring of physical activity. Diabetes Educ. 2006; 32(1):69-77.

24. McAuley E. Self-efficacy and the maintenance of exercise participation in older adults. J Behav Med. 1993:16(1):103-13.

25. Oman RF, King AC. Predicting the adoption and maintenance of exercise participation using self-efficacy and previous exercise participation rates. Am J Health Promot. 1998;12(3):154-61.

26. Trost SG, Owen N, Bauman AE, Sallis JF, Brown W. Correlates of adults' participation in physical activity: review and update. Med Sci Sports Exerc. 2002;34(12):1996-2001.

27. Sallis JF, Hovell MF. Determinants of exercise behavior. Exerc Sport Sci Rev. 1990;18:307-30.

28. Verwey $R$, van der Weegen $S$, Spreeuwenberg $M$, Tange $H$, van der Weijden T, de Witte L. Upgrading physical activity counselling in primary care in the Netherlands. Health Promot Int. 2016;31(2):344-54.

29. Whitlock EP, Orleans $C T$, Pender N, Allan J. Evaluating primary care behavioral counseling interventions: an evidence-based approach. Am J Prev Med. 2002;22(4):267-84.

30. Muntaner-Mas A, Vidal-Conti J, Borras PA, Ortega FB, Palou P. Effects of a Whatsapp-delivered physical activity intervention to enhance health-related physical fitness components and cardiovascular disease risk factors in older adults. J Sports Med Phys Fitness. 2017:57(1-2):90-102.

31. Eakin EG, Glasgow RE, Riley KM. Review of primary care-based physical activity intervention studies: effectiveness and implications for practice and future research. J Fam Pract. 2000;49(2):158-68.

32. Benjamin $\mathrm{K}$, Donnelly $\Pi$. Barriers and facilitators influencing the physical activity of Arabic adults: a literature review. Avicenna. 2013;2013(1):8

33. Egan AM, Mahmood WAW, Fenton R, Redziniak N, Kyaw Tun T, Sreenan S, McDermott JH. Barriers to exercise in obese patients with type 2 diabetes. QJM. 2013;106(7):635-8.

34. Serour M, Alqhenaei H, Al-Saqabi S, Mustafa A-R, Ben-Nakhi A. Cultural factors and patients' adherence to lifestyle measures. Br J Gen Pract. 2007; 57(537):291-5.

35. Al-Mohannadi A, Al-Kuwari M. The effect of weather conditions on the seasonal variation of physical activity, vol. 4; 2015.

36. Bélanger M, Gray-Donald K, O'Loughlin J, Paradis G, Hanley J. Influence of weather conditions and season on physical activity in adolescents, vol. 19; 2009

37. Ministry of Health Oman. 7th five year health development plan. Muscat: Ministry of Health; 2006.

38. Oman Health Vision 2050. 2012.

\section{Publisher's Note}

Springer Nature remains neutral with regard to jurisdictional claims in published maps and institutional affiliations.

\section{Ready to submit your research? Choose BMC and benefit from:}

- fast, convenient online submission

- thorough peer review by experienced researchers in your field

- rapid publication on acceptance

- support for research data, including large and complex data types

- gold Open Access which fosters wider collaboration and increased citations

- maximum visibility for your research: over $100 \mathrm{M}$ website views per year

At BMC, research is always in progress.

Learn more biomedcentral.com/submissions 